\title{
Laboreal
}

Volume $5 \mathrm{~N}^{\circ} 2$ | 2009

Varia

\section{¿Explica el trabajo la sociedad ? : en torno a la sociología del salariado de Pierre Naville}

Explica o trabalho a sociedade? : à volta da sociologia do assalariado de Pierre Naville

Le travail explique-t-il la société ? : a propos de la sociologie du salariat de Pierre Naville

Does work explain society?: around the sociology of employment of Pierre Naville

Jorge García López

\section{(2) OpenEdition}

Journals

Edición electrónica

URL: http://journals.openedition.org/laboreal/9490

DOI: 10.4000/laboreal.9490

ISSN: 1646-5237

\section{Editor}

Universidade do Porto

Referencia electrónica

Jorge García López, « ¿Explica el trabajo la sociedad ? : en torno a la sociología del salariado de Pierre Naville», Laboreal [En línea], Volume 5 №2 | 2009, Publicado el 01 diciembre 2009, consultado el 10 octubre 2019. URL : http://journals.openedition.org/laboreal/9490 ; DOI : 10.4000/laboreal.9490

Este documento fue generado automáticamente el 10 octubre 2019.

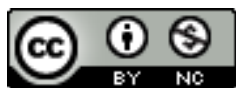

Laboreal está licenciado com uma Licença Creative Commons - Atribuição-NãoComercial 4.0 Internacional. 


\section{¿Explica el trabajo la sociedad ? : en torno a la sociología del salariado de Pierre Naville}

Explica o trabalho a sociedade? : à volta da sociologia do assalariado de Pierre Naville

Le travail explique-t-il la société ? : a propos de la sociologie du salariat de Pierre Naville

Does work explain society?: around the sociology of employment of Pierre Naville Jorge García López

\section{NOTA DEL EDITOR}

Manuscrito recebido em : Julho/2009

Aceite após peritagem : Setembro/2009

1 La pregunta del título [1] remite inmediatamente a otras : ¿qué "sociedad" es la que se explicaría por qué "trabajo"? ¿Se trata de la referida en los discursos ministeriales y jurídicos de nuestras naciones? Cabría entonces descomponerla, como estos hacen, en diferentes ámbitos, tantos como las instituciones y políticas tratasen de intervenir y regular. Y, así, aplicarnos a diferentes sociologías (de la familia, de la escuela, del ocio, del turismo, de la mujer, de la inmigración, del trabajo, etc.) adecuadas a la dilucidación de fenómenos presuntamente específicos a cada una de dichas esferas. En este marco el "trabajo" de una "sociología del trabajo" podría aspirar a algún un privilegio epistémico en la medida y circunstancias en que los ámbitos laborales, de la producción material o de la empresa se nos revelasen como social y políticamente más importantes que el resto para el devenir del conjunto de la nación. En general, cabe pensar que este, precisamente, ha sido el marco en el que se ha venido dirimiendo el auge (de los años cuarenta hasta los años setenta del pasado siglo) y la crisis (desde la década de los 
ochenta) de una especialidad como la Sociología del Trabajo. La pérdida o la recuperación de la centralidad del "mundo del trabajo" en los discursos que las naciones se hacen de su propio desarrollo señalarían los puntos de inflexión del valor relativo de la especialidad y su "trabajo" frente a los objetos de las especialidades rivales [ $\left.{ }^{2}\right]$.

2 Y, no obstante, se pueden pensar otras "sociedades" formalizables por la sociología (y bien distintas a la que el Estado-Nación y el sentido común nos coloca todos los días tanto en los boletines oficiales como en las secciones de los noticiarios y los periódicos) $y$, con ellas, otra centralidad a conquistar por el "trabajo". ¿Y si esta centralidad remitiese a la incapacidad para explicar sin su concurso las articulaciones procesuales entre los más variados conjuntos de fenómenos sociales ("laborales" o no) para una sociología a secas? Claro que en este caso, como la "sociedad", el "trabajo" sociológicamente pertinente merecería a su vez ser repensado. Este es precisamente el ejercicio con el que vamos a empezar, apoyándonos para ello en un autor largamente reivindicado y citado en los últimos decenios en Francia : Pierre Naville (en lo sucesivo PN) [3].

4 En demasiadas ocasiones los sociólogos del trabajo nos hemos remitido a una actividad humana productora de bienes y servicios, considerada como presentando un carácter ontológico y transhistórico para, a renglón seguido, conformar los datos relevantes a partir de la observación directa del trabajo concreto. Nuestro objeto vendría dado por una acción colectiva que se presupone como central, desde un punto de vista tanto material como ideal, en la conformación de toda sociedad conocida. Según esta definición de "trabajo", la acción y el actor, formarían una unidad indisociable : una praxis. La metodología pasaría entonces por el análisis de la "situación de trabajo", esquema cuadrangular que comprendería las relaciones entre el trabajador colectivo, sus herramientas, sus materiales y el resultado (obra o producto) de su actividad. Esquema dinamizado por las relaciones sociales que se trabarían en torno, o a propósito de, el trabajo "concreto" desplegado por ese trabajador colectivo en unos o en otros procesos de trabajo [ $\left.{ }^{4}\right]$.

5 El método aplicado por PN en sus investigaciones contrasta poderosamente con el anterior. El objeto sustantivo de investigación ya no es la actividad humana genérica productora de bienes y servicios sino el salariado. El salariado comprendería un modo, históricamente específico, en el que las colectividades contemporáneas aprecian y reparten los tiempos sociales y, por este medio, dichas colectividades se reproducen y renuevan, transformándose, a sí mismas. La sociología de PN tratará de apuntar así al análisis de mecanismos mediante los cuales se miden y se determinan socialmente, en la modernidad, las relaciones entre los miembros de lo colectivo, las distribuciones de sus actividades y las proporciones de movilización y de uso de sus tiempos sociales. El método pasa aquí por la interrogación simultánea de las formas adoptadas por la división técnica del trabajo como por las formas adoptadas por la división social de los trabajadores. División técnica y social del trabajo serán consideradas por PN como dos perspectivas diferentes volcadas sobre los mismos fenómenos: los modos de movilización social de los tiempos de los individuos (modos que atraviesan tanto los ámbitos productivos como los reproductivos), y los modos de vertebración del conjunto de los intercambios y los repartos de la riqueza social (modos que atraviesan también ambos espacios). 
6 Para este análisis del salariado el trabajo concreto del trabajador colectivo está muy lejos de suponer, fenomenológicamente hablando, una realidad primordial, ese lugar lo ocuparía más bien el salario: salario que liga, en la modernidad capitalista, unas condiciones de uso (producción) de las capacidades laborales de los miembros de la colectividad con unas condiciones de consumo, formación y ocio (reproducción) para sus prestatarios. Es pues el carácter salarial del trabajo contemporáneo (las condiciones en las que esas capacidades laborales se intercambian y reparten) el que condiciona los modos de movilización social de los trabajadores asalariados (directamente) y sus familias (indirectamente), así como su participación en los procesos de circulación de los bienes y servicios. La formalización en claves relacionales de este específico modo de puesta en relación de tiempos, actividades y recursos sociales heterogéneos, esto es, la relación salarial, presupone entonces la separación estructural entre el conjunto de los operadores (trabajadores) -las condiciones de habilitación y reproducción sociales de las capacidades de dichos operadores- y el conjunto de los lugares productivos (puestos de trabajo) disponibles para su potencial ubicación condicional -las condiciones sociotécnicas de la conformación productiva de dichos lugares.

7 Sería entonces únicamente a partir de la consolidación histórica de la separación o ruptura entre trabajos y trabajadores, momento caracterizado por la generalización de la producción y la distribución del conjunto de la riqueza social y la movilización de las capacidades laborales de los individuos bajo la forma de mercancías, cuando el trabajo "en general", el trabajo "social" o el trabajo, con independencia de las formas concretas, inmediatas, que revistan sus aplicaciones productivas, se convierte en una categoría socialmente operante y sociológicamente central. La centralidad sociológica del trabajo no es, en PN, la centralidad de ninguna actividad humana ontológica sino la ligada a un conjunto, históricamente específico, de relaciones sociales. Especificidad, por la cual, las actividades y los tiempos de las personas resultan descompuestos, distribuidos, disputados y renovados en la modernidad: relaciones implicadas por la extensión histórica de un trabajo, el trabajo asalariado, que opera como mediación entre capacidades individuales y necesidades sociales, entre valores de uso y valores, condicionando las formas sociales que adopta la existencia de los miembros de la colectividad.

8 Partiendo de estas breves indicaciones puede vislumbrarse desde ya la deuda que la perspectiva navilliana guardaría con los trabajos teóricos de uno de los clásicos de la sociología más injustamente olvidados en la actualidad: el Karl Marx posterior a 1847. La particular recuperación sociológica de las principales categorías de El Capital efectuada por PN en su Tesis, De l'aliénation à la juissance (Naville, 1957), trata de explicitar dicha deuda. Las categorías de trabajo "simple" y "complejo" y de trabajo "productivo" e "improductivo", eran allí revisitadas por PN en claves esencialmente relacionales, a la luz de las distinciones previas entre trabajo "concreto" y "abstracto" y de "trabajo" y "fuerza de trabajo". En esta otra trama teórica, las hipótesis relativas a las reglas del juego social en la modernidad no pivotan en torno al trabajo entendido como praxis humana ontológica sino al "trabajo abstracto" (y el "valor"). Y el "trabajo abstracto" es una categoría que remite, en Marx, a una operación de puesta en común, comparación y medida sociales de todas las actividades laborales (fuerzas de trabajo) y todos sus resultados (mercancías), las unas por los otros y viceversa.

9 Entendido de este modo el "trabajo abstracto" ni remite a, ni precisa de, un trabajo desprovisto de contenido (complejidad, saber-hacer, cooperación, etc.) : trabajo que, 
tan cargado como descargado se quiera de esa "sustancia" (autonomía), seguiría siendo aún "trabajo concreto". Por tanto, el "trabajo abstracto", el trabajo social o el trabajo en general, ni deriva de, ni se agota en, los ámbitos concretos e inmediatos de la producción material : dicha operación social implica tanto a la producción como al consumo; tanto a la producción como a la circulación y a la distribución; tanto a la producción industrial de mercancías como a la producción social de fuerza de trabajo. En otras palabras, en esta otra trama teórica no hay más "trabajo en general" que el "trabajo abstracto" y éste último supone tanto una producción generalizada de bienes y servicios en calidad de mercancías como la generalización de la compra-venta de fuerza de trabajo. En estas otras claves, todo lo relativo al trabajo sería ya, en el modo de producción capitalista, objeto de medidas sociales. Así, dicha trama categorial es considerada como un intento de formalización de relaciones entre movimientos (movilidades e circulaciones que atraviesan tanto la producción como la distribución y el consumo) característicos, exclusivamente, de la modernidad capitalista. Se trata con ello de una relectura sociológica de la obra madura de Marx que presenta, a nuestro entender, antecedentes previos en la obra de, por ejemplo, Isaac Illich Rubin (1928), así como importantes paralelismos con las recientes investigaciones teóricas (comúnmente referidas bajo la etiqueta de la "nueva lectura de Marx") de, por ejemplo, Moishe Postone (2006) y Michael Heinrich (2008).

11 Estas relecturas contrastan críticamente con el Marx habilitado como su referente por el modo de proceder teórico-metodológico característico de la Sociología del Trabajo clásica: el que aquí denominaremos (siguiendo a Pierre Rolle -el más estrecho colaborador hasta su muerte de PN) con el término de "Primera Formalización" [ ${ }^{5}$. Para este tipo de formalización, una realidad presupuesta, entendida como dada y evidente (el "trabajo realmente existente"), se representa en el concepto (la praxis humana ontológica), mediante los datos generados por la aplicación de una determinada metodología de observación (la "situación de trabajo"). La especificidad de la problematización sociológica propia de la especialidad encuentra así su aval en la delimitación sensible de un ámbito de lo real (los procesos productivos), sobre el que esta Sociología del Trabajo (concreto) podría acumular múltiples descripciones y datos. De aquí, la posibilidad de sumarle los datos resultantes de la aplicación de otras "metodologías": las de la psicología, la ergonomía, las teorías organizacionales, etc., engordando así la promesa de una plurisdiplinariedad ilusoria (que pretendiendo estar hablando de lo mismo -el trabajo- lo hace en realidad de "trabajos" muy diferentes).

El "trabajo realmente existente" (el trabajo asalariado, en primer lugar, pero también el trabajo "doméstico", "informal", "voluntario", etc.) es interpretado entonces a la luz de la unidad, la postulada en el concepto (praxis humana instituyente), entre el trabajo y el trabajador, entre el actor y su acción. El trabajador artesano y los oficios (en tanto encarnación histórica del carácter naturalmente práxico -y, por ende, reflexivo y autónomo- de toda actividad humana productiva) han ocupado generalmente, para la Sociología del Trabajo clásica, el lugar del tipo-ideal desde el que evaluar las distancias entre el concepto y las realidades (temporales) a él coyunturalmente ligadas como su expresión necesaria. Los diagnósticos tienden a plantearse, en este caso, en términos de alienación: el análisis sociológico se resuelve en la denuncia de la arbitrariedad presumiblemente inscrita en la separación coyuntural (heteronomía en el trabajo) de "lo naturalmente uno". El sentido del movimiento del trabajo pasaría por la necesaria e 
inevitable recuperación, en unas u otras formas, de dicha unidad (autonomía en el trabajo) artificialmente suspendida. La hipótesis implícita que arma el esquema interpretativo aplicado sobre el movimiento histórico de este otro "trabajo" es generalmente la de una determinación natural de las divisiones sociales del trabajo y de los trabajadores por la conformación infraestructural de las divisiones técnicas del primero en los procesos de trabajo.

Como el objeto (la praxis humana) es supuesto permaneciendo idéntico a sí mismo en lo esencial, a lo largo de la historia, la interpretación de la distancia entre el mismo y sus manifestaciones concretas (el trabajo realmente existente) se ligarán, en esta Primera Formalización, a la acción de factores simultáneamente externos y anteriores al mismo : el "desarrollo tecnológico", para la escuela humanista (Georges Friedmann, Alain Touraine, Pierre Durand, etc.), y la "lucha de clases", para las escuelas marxistas posteriores (Harry Braverman, Michael Freyssenet, Benjamín Coriat, Robert Linhart, etc.). En el primer caso, la sustitución de la herramienta por la máquina determinaría la transformación histórica de la otrora situación de trabajo "autónoma", del trabajador artesano, hacia una situación de trabajo heterónoma, para un trabajador ahora asalariado. Trabajador para el cual su actividad ya no viene organizada por el colectivo obrero (por el oficio) sino por los departamentos de estudio y planificación del trabajo. El trabajo heterónomo resultaría el producto del progreso científico-técnico en sí y por sí mismo : hipótesis evidentemente para-sociológica y pistoletazo de salida inicial para todos los determinismos tecnológicos por venir. En el segundo caso serían la propiedad ("privada") de los medios de producción y la apropiación ("no-equivalente" o "injusta") de los resultados de las actividades laborales humanas, las que impondrían una utilización alienante de la tecnología, propiedad y apropiación ligadas a la emergencia histórica de la clase burguesa e impulsadas por los específicos "intereses" de la misma. Hipótesis, por su parte, inverosímil que supone el trabajo heterónomo como producto de la actuación de una clase "capitalista" que se habría autogenerado, primero, para conformar la producción y, por ende, la sociedad, en función de sus intereses, después.

Tras este esquema de una diáspora coyuntural (alienación) forzada por la acción de uno de ambos factores "externos" -el "desarrollo científico-técnico" y/o la "clase"- sobre un trabajador colectivo predestinado, no obstante, a su fusión con su actividad, nos encontraríamos ante una forma particular, con una dilatada historia, de resolución de los problemas planteados por la Economía Política. Efectivamente, este modo de formalización se ha apoyado, desde un principio (en polémica con los planteamientos de sus homólogos norteamericanos de la Escuela de las Relaciones Humanas: Fritz Roethisberg, William J. Dickson, Elton Mayo), en los postulados de la Economía Política Clásica (el trabajo del trabajador como la fuente y patrón natural de medida de toda la riqueza social material), tratando, desde ellos, de defender el carácter sociológicamente central del ámbito de la producción (y de las relaciones sociales directas e inmediatas trabadas en él) frente a los postulados de la Economía de tipo Neoclásico. La autonomía que esta última proyectaría sobre las relaciones mercantiles contemporáneas de intercambio podría entonces desvelarse como "ficticia" y "coyuntural" : los mercados distorsionarían unas relaciones de equivalencia predeterminadas "naturalmente" por las cualidades y las cantidades de los trabajos concretos desarrollados por el trabajador colectivo. La Sociología podría, y debería, así prescindir del análisis de las formas sociales adoptadas por la circulación de los productos sociales para centrarse en las condiciones concretas en las que el trabajo del trabajador colectivo (supuesta fuente 
transhistórica de toda la riqueza social y único patrón de medida para su reparto social) es movilizado y consumido en los procesos de producción.

Tal y como PN subrayó en varias ocasiones, dicho planteamiento encuentra un desarrollo pionero en la obra de Pierre-Joseph Proudhon [6]. Según Proudhon los intercambios podrían ser intercambios de mercancías efectuados por trabajadores que se emplearían a sí mismos en cooperativas (no venderían sus capacidades a terceros) y que recibirían en el cambio de sus productos contra los productos ajenos el estricto equivalente de las horas de trabajo invertidas en su producción (nadie se apropiaría así de más tiempo de trabajo ajeno por menos tiempo de trabajo propio). Partiendo de esta hipótesis sería cuando "propiedad" (colectiva o privada) de los medios de producción y "apropiación" (equivalente o no-equivalente) de las riquezas resultantes del empleo del tiempo de los otros, conformarían las categorías clave que marcarían el transito de una producción "mercantil simple" (recuperable) a una producción "capitalista" (reversible). Los intercambios generalizados en términos de valores equivalentes, no constituirían, en sí mismos, la matriz de ningún conflicto (explotación), sino que éste encontraría su origen en su gestión puramente mercantil (espontánea y caótica) bajo el imperio del monopolio de la propiedad privada de los medios de producción y de la consiguiente "apropiación" (o robo) a través de un intercambio desigual de tiempos de trabajo.

Para el Marx rescatado por PN, sin embargo, monetarización del conjunto de las necesidades sociales, producción generalizada de bienes y servicios como mercancías y compra-venta de fuerzas de trabajo que reciben sus propios precios en unos mercados específicos (los mercados de trabajo), conforman un mismo y único proceso histórico e implican una explotación trabada, precisamente, en el intercambio generalizado de valores equivalentes y no en su quiebra coyuntural por "el mercado". Las categorías centrales en este otro planteamiento no serían las de "propiedad" y "apropiación" sino las de "valor" y "trabajo abstracto", categorías que no remiten a la "producción material" sino al conjunto de unas relaciones sociales de producción, distribución, circulación y consumo históricamente específicas. Por consiguiente, la centralidad sociológica del eterno trabajo humano ontológico (o praxis) -y, con él, de las divisiones técnicas del trabajo sobre las sociales- se nos escurre entre los dedos : esa centralidad sería para PN, en el Marx de El Capital, la de un trabajo históricamente específico, el trabajo asalariado. En contraste, en el marco de la Primera Formalización, la escisión que acabamos de cuestionar implícitamente entre Economía y Sociología se reproduce bajo nuevas formas. Concretamente bajo estas : la producción, por un lado ; los intercambios, por el otro. La verdad (el pasado y el futuro : la regla verdadera y justa, necesaria, del juego social) estaría en la producción (el "trabajo") ; la mentira (el presente : la regla falsa e injusta, contingente, del juego social) estaría en la distribución y el intercambio (el "mercado"). Tendríamos entonces la "buena" Sociología enfrentada con la "mala" Economía: de un lado, el trabajo como "actividad ontológica o praxis" (verdad atemporal); del otro, el trabajo como "factor de producción" o "mercancía" (falacia contingente). La "buena" Sociología se prepararía así para encerrarse en los procesos de trabajo y deducir, a partir del análisis directo del trabajo concreto, fuente supuesta de toda la riqueza y de todos los valores, la arquitectura armonizada de lo social. Arquitectura dinamizada entonces por un movimiento, por una ley de evolución, que se suspende en una temporalidad ahistórica (relativa al siempre); si bien "asaltada" y "bloqueada" coyunturalmente, en lo que a sus formas contemporáneas se refiere, por el 
desarrollo científico-técnico y/o las luchas de clases (lo que explicaría el "trabajo realmente existente"). acabamos de caracterizar), y los planteamientos "postindustrialistas" o "postfordistas" posteriores, se puede constatar a partir de la generalización del análisis de la "situación de trabajo", operada por estos últimos, sobre un conjunto cada vez más amplio de relaciones sociales. En estos planteamientos, la necesidad de mirar más allá de los talleres y las situaciones de trabajo industriales se apoya en la progresiva pérdida de la exclusividad de los ámbitos fabriles para los procesos de alienación de la actividad humana (separación entre el productor y sus obras). Aquella misma alienación será supuesta como expandiéndose sobre un conjunto cada vez más amplio de actividades sociales que, en lo sucesivo, darían lugar a una "sociedad programada" (Alain Touraine) o una "sociedad fábrica" (Operaismo Italiano -Raniero Panzieri, Mario Tronti, Toni Negri, etc.-). A nuestro parecer, la persistencia de dicho método habría venido hipotecando las explicaciones relativas al movimiento de nuestro objeto, sustituyéndola por una descripción de las supuestas transformaciones del "trabajo" mismo : bien una conversión de la actividad humana ontológica en "prestación servicial" autónoma (cuyo modelo implíito es el del trabajo doméstico; las actividades de cuidado de sí y de los otros, privilegiadas, por ejemplo, por André Gorz), bien una mutación de la anterior en "comunicación" (cuyo modelo se apoya en las nuevas profesiones altamente cualificadas: las actividades de programación, diseño, publicidad, gestión, marketing, creación, etc., privilegiadas por los autores del "trabajo inmaterial").

La centralidad sociológica de ambas metamorfosis del "trabajo" para la evolución de conjunto de la estructura social contemporánea se apoyan entonces en el crecimiento estadístico registrado por los empleos terciarios. El horizonte al que apunta el movimiento, en los dos casos, sigue siendo el de la desalienación del "trabajo": el productor y su actividad se ligarían de nuevo inextricablemente, tanto en la prestación servicial como en la actividad inmaterial de carácter comunicacional, con los resultados de esas actividades, con sus obras, resultando el trabajo de estos trabajadores imposible de medir (de "racionalizar") socialmente. En estas nuevas realidades emergentes, por tanto, los mercados, las instituciones (empresariales, formativas, financieras, etc.) y el Estado, operarían cada vez más como puros mecanismos de dominación desnudos : se trataría de "contextos" progresivamente inadecuados (desde un punto de vista funcional o estructural) frente al proceso impulsado por las mutaciones cualitativas sufridas por el trabajo concreto. En otras palabras, si bien la crisis progresiva del Movimiento Obrero tradicional ha motivado la búsqueda de nuevos relevos (el "obrero social", "los “jóvenes", las “mujeres", los "estudiantes", el general intellect, etc.), éstos se encuentran ahora más allá del taller y la producción industriales mediante la aplicación 
del mismo modo de formalización que ha venido haciendo de los ámbitos "infraestructurales", de las formas de utilización productiva del trabajo concreto (divisiones técnicas), la clave explicativa de las transformaciones generales que sacuden el conjunto de las divisiones sociales.

En contraste, la necesidad de mirar más allá del taller, los procesos de trabajo y la industria, hacia los ámbitos reproductivos, las instituciones y el Estado, era reivindicada por PN en la década de los cincuenta a partir de claves muy diferentes. En La vie travail et ses problèmes (Naville, 1954), investigación con la que nuestro autor inauguraba sus aportaciones empíricas en el ámbito de la Sociología del Trabajo, la prolongación cuantitativa en número y extensión de la vida de trabajo del conjunto de la población se ligaba con la emergencia de los nuevos mecanismos (cotizaciones sociales e impuestos, negociación colectiva, prestaciones sociales) encargados en lo sucesivo de regular las condiciones de reproducción y movilización productiva de (cada vez más) grandes agregados de fuerzas de trabajo. En este contexto, las características concretas de las actividades laborales no resultaban ya una variable autosuficiente para la dilucidación de las condiciones de movilización y de participación en la riqueza social de los trabajadores a ellas ligados. En dicha investigación, tres procesos reclamaban, para PN, de su puesta en relación por parte de la sociología: a) las transformaciones socio-económicas que estaban afectado a la cantidad y la extensión de los tiempos de la vida activa ; b) la aplicación socio-institucional de los nuevos mecanismos de regulación de la reproducción y, sobre manera, de la formación de las poblaciones ; y, c) los efectos ambivalentes, simultáneamente profesionalizantes y desprofesionalizantes, de las nuevas formas de movilización de las fuerzas de trabajo ligados a dichos mecanismos de reproducción[ $[7]$. IV

23 En relación con el segundo de nuestros objetos formales, precisamente los análisis inmediatamente posteriores de PN, Automation et travail humain (Naville et al., 1961) y Vers l'automatisme social ? (Naville, 1985 [1963]) invertirán el sentido del abordaje de esas mismas relaciones (entre producción, distribución, intercambio y consumo) al centrarse en los procesos de automación industrial. Aquí serán las divisiones técnicas del trabajo las analizadas, en primera instancia, pero para ser sistemáticamente problematizadas a la luz de su relación con las transformaciones que sacudían las divisiones sociales previamente referidas (La insistencia, reiterada una y otra vez por el autor, en la necesidad de la inserción en el análisis del factor tecnológico en la trama de relaciones sociales específicamente capitalistas encuentra su traducción en, precisamente, dicha problematización).

24 Según PN el movimiento inmanente a la relación (salarial) se caracterizaba, como ya hemos indicado, por la separación del trabajador de su trabajo. Este "movimiento", en lo que respecta a la división técnica (o manufacturera) del trabajo vigente hasta la segunda mitad del siglo XX, esto es, a su fragmentación en tareas parcelarias (la promovida por la aplicación de la OCT), estaba ligado con la discontinuidad operatoria de los medios de producción automatizados, discontinuidad en la cual el ser humano hacía las veces de nexo de unión. Esta forma de división se inscribía en una determinada forma social de división entre clases (económicas, de sexo y edades). Las formas actuales, cada vez más mecanizadas, de los procesos productivos estarían volviendo progresivamente caducos los términos de división o subdivisión en lo relativo a las formas de reparto y movilización de los trabajadores dentro de los 
procesos de trabajo. La institucionalización del salariado, asociada con las consecuencias de la automación, se manifestaría así en una disociación creciente entre el trabajo de las máquinas y el trabajo de los hombres. De hecho, para PN, en lo relativo a sus análisis sobre la automación, el principio que pasará poco a poco a regir en aquellos procesos de más alta productividad será el de una distribución por funciones móviles (en detrimento de la tradicional división de tareas), lo que abría la posibilidad de nuevas combinatorias, en formas inéditas, entre funciones, puestos y tareas y socializaciones, formaciones y capacidades.

Podríamos sintetizar los resultados de estas investigaciones en cuatro grandes conjuntos: a) los relativos a las nuevas formas de distribución del trabajo en las empresas sobre equipos constituidos por categorías diversas de personal y la cooperación necesaria que dicha distribución implicaba ; b) la fluidez, ampliada, para la mano de obra y su gestión a lo largo no ya sólo de departamentos o empresas diferentes sino de distintos mercados de trabajo sectoriales, así como la transversalidad creciente de los saberes técnico-científicos, formalizados, necesarios en la producción; c) transversalidad que se encontraba estrechamente ligada con la creciente penetración de los servicios en el conjunto de la industria y de la producción ; y d) interpenetración que se despliega en una reticularización de los procesos productivos en donde la empresa pierde su forma tradicional para devenir un nudo coyuntural entre secuencias y procesos que condicionan cada vez más su permanencia, transformación o desaparición [8]. En consecuencia : si la distancia conquistada técnicamente por dichas conexiones automatizadas respecto de la organización propiamente humana de la producción se está ampliando, el análisis centrado en los procesos de trabajo (e incluso en las empresas) se bastará cada vez menos para dar cuenta de las configuraciones que, previsiblemente, podrían adoptar los grupos de asalariados. Sería necesario, en lo relativo a las personas y su gestión productiva, la observación también de las divisiones propiamente sociales que, diferenciándolos los unos de los otros y jerarquizándolos entre sí desde fuera de la producción, contribuirán poderosamente, y cada vez más (dado el decreciente peso de los determinismos propiamente técnicos sobre la misma), a orientar su gestión y distribución dentro de ésta [ $\left.{ }^{\circ}\right]$.

Al hilo de éstas investigaciones, varios artículos parciales, posteriormente compilados, en los años setenta, junto a una reedición de la primera parte de La vie de travail..., en Temps et technique (Naville, 1972a), tratarán también de redimensionar el fenómeno de la terciarización productiva en polémica con los diagnósticos, por entonces incipientes, relativos a la progresiva transformación de la "sociedad industrial" en una futura "sociedad de servicios". Dada la ya señalada persistencia, a lo largo de las décadas ulteriores, de planteamientos similares, las indicaciones críticas de PN presentan aún una sorprendente actualidad. Dos cuestiones importantes resultan interpeladas en esas críticas : a) los empleos terciarios no conforman, en sí mismos, un sector autónomo del secundario y que se expanda en relación directa a la contracción de éste $\left[{ }^{10}\right]$; b) la proliferación de dichos empleos tampoco supondría, por sí misma, ninguna quiebra estructural de las posibilidades de comparación y medida del conjunto de los bienes y servicios y de las fuerzas de trabajo. La primera objeción se apoya en la distinción conceptual entre tipos de establecimientos (ramas, sectores) y tipos de empleo (profesiones, formaciones): tanto el proceso de socialización del salario como el proceso de automación productiva dilatan, cada vez más, esta conexión aparente, provocando una no correlación creciente entre las distribuciones de los asalariados agrupados por sectores de actividad y/o tipos de establecimiento y las mismas 
distribuciones según familias de empleos o profesiones [11]. La segunda remite (como el autor pone de manifiesto en sus análisis sobre la industria informática de la época) a la consideración de la dimensión abstracta del trabajo contemporáneo como ligada con la específica naturaleza social del conjunto de los intercambios dominantes : persiste una división del trabajo, en lo sucesivo extendida a escalas internacionales, articulada por una vertebración de la producción con el consumo mediada por el intercambio de mercancías socialmente comparadas en términos de equivalencia en valor. La naturaleza más o menos indirecta (supervisión y mantenimiento), informacional (programación, organización y diseño) o social (cooperación, comunicación y/o motivación) del trabajo inmediato de los asalariados seguiría aquí remitiendo a la dimensión "concreta" de sus trabajos. La aplicación de medidas sociales sobre unas y otras fuerzas de trabajo (aplicadas a un trabajo material o inmaterial), desde la comparación y jerarquización de diferentes situaciones de vida y formación -"tiempos de trabajo socialmente necesarios"-, continuará produciéndose mientras esas capacidades laborales se intercambien frente a un capital dando lugar a un plusvalor.

Pero, en primera instancia, el blanco implícito de las críticas navillianas, en sus investigaciones sobre la automación productiva, era fundamentalmente otro: los análisis pioneros de la maquinización del trabajo industrial capitalista realizados por la escuela friedmanniana. Según éstos, el origen de la alienación en el trabajo para el conjunto de los trabajadores asalariados remitiría a una mecanización parcial de los procesos de trabajo. Dicha alienación se encontraría, no obstante, condenada a desaparecer en la medida en que la síntesis maquínica de tareas productivas, la pretendidamente inscrita en el proceso de eliminación de las herramientas artesanales movidas por la mano, la voluntad y el conocimiento del obrero, se extienda a la totalidad de los procesos de trabajo. Momento en el cual el colectivo obrero, liberado de una ejecución directa en tareas subordinadas, pasaría de nuevo a controlar potencialmente el proceso de trabajo al situarse "por encima" de dichas máquinas, controlándolas. PN remite, al respecto, abiertamente a los argumentos críticos de Marx frente a Proudhon: la máquina no representa ninguna síntesis de tareas -sino de herramientas, movidas por una fuente de energía externa- ; la autonomía perdida del artesano, que aquí se utiliza para la dilucidación el carácter específicamente social del "trabajo" asalariado industrial, presupone una coherencia interna del "trabajo" humano, por debajo de sus diferentes formas históricas, contingentes -es decir, que termina por separar el trabajo de la trama de relaciones sociales en las cuales este encuentra su significación social- (Cf. Naville, 1985 [1963]). Ambas críticas implican un cuestionamiento radical tanto de la "situación de trabajo" como del "modelo del oficio" desde el punto de vista de la operacionalización sociológica.

Esta hipótesis, la de una desalienación posible y, a la par, inevitable, posibilitada por el maquinismo, encontrará posteriormente nuevos desarrollos en el ámbito de la Sociología del Trabajo a lo largo de las décadas de los ochenta y noventa. Muchos "postfordistas" (Host Kern y Michael Schumann, Benjamín Coriat, Charles Sabel y Michael-J. Piore) la rescatarán bajo diferentes formas (nuevas pautas de "racionalización industrial", nuevos modelos de "desarrollo industrial" -la especialización flexible-) : en este caso, presumiblemente dinamizada por "cuadrados mágicos" o nuevas "trayectorias tecnológicas" ligadas tanto con las Nuevas Tecnologías de la información como con la nueva flexibilidad productiva impuesta por unos consumos caprichosos y cambiantes. También en estos casos los trabajos de los trabajadores son supuestos como aplicándose sobre nuevas funciones, más amplias, y 
desplegando nuevos conocimientos, cada vez más inseparables de la socialización informal y directa del colectivo obrero en las "culturas" que subyacen tras los diferentes tipos de productos, profesiones, establecimientos y territorios. El horizonte del movimiento del "trabajo" es recortado, de nuevo, partiendo de la inevitable restitución del vínculo que ligaba naturalmente (en el modelo del oficio artesanal) al trabajador con sus puestos de trabajo y sus organizaciones a través de sus "trabajos".

Otra de las problemáticas que han venido poniendo a prueba los límites heurísticos de la Primera Formalización, en estrecha continuidad con los argumentos precedentes, remite al tercero de nuestros objetos formales: la cualificación. La Sociología del Trabajo clásica, tanto en sus versiones humanistas como marxistas, ha convenido generalmente en ligar esta última con el contenido del "trabajo" y, por ende, con la tecnología y los conocimientos "reales" que exige, para el trabajador, su prestación, control y dominio. Sin embargo, la cualificación remite también, a todas luces, a una baza movilizada por éstos en una competición que se efectúa en sus respectivos mercados de trabajo : nos encontraríamos ante la necesidad de diferenciar entre una cualificación "efectiva" y/o "real" y otra "formal" o "ficticia", se dirá entonces. La primera remitiría a los conocimientos realmente necesarios para el trabajo concreto (los determinados por y desde la producción); la segunda a la reconocida formalmente en el organigrama y las clasificaciones de la empresa y relacionada con las credenciales educativas (reconocimiento afectado por estado de los mercados de trabajo).

El escenario que de este modo nos disponemos a dibujar para la sociedad contemporánea resulta inverosímil: la estructura de los puestos, por un lado, dinamizada por la tecnología y la organización empresarial de los procesos de trabajo (dando como resultado ineluctable una descualificación "real"); el reparto de los puestos entre los trabajadores, por el otro, dinamizado "por las relaciones de poder" en los mercados laborales y en las instituciones educativas (dando como resultado una recualificación "formal" o ficticia) : ambos movimientos resultando indiferentes el uno del otro. Todo lo más : el segundo enmascararía ideológicamente el primero al separar simbólicamente las cualificaciones de su pretendido origen natural, la organización del proceso de trabajo y la tecnología. Resultado : la forma en que se concibe la producción (los procesos de trabajo) resultaría determinante sobre la forma en que se concibe su reparto entre los intervinientes en el proceso de trabajo. 0 , en otros términos, la división técnica del trabajo sobredeterminaría "realmente" las divisiones sociales del mismo; la madre de todas las batallas estaría en la producción material (infraestructura), en el proceso de trabajo, en el taller y en el trabajo concreto.

Inverosímil, puesto que, de entrada, la hipótesis opuesta (que la división social de los trabajadores contribuyese a conformar, a su vez, las características de la división técnica del trabajo) encuentra demasiados avales como para resultar igualmente acertada. Tal es una de las críticas centrales a los planteamientos sustancialistas sobre la cualificación efectuadas por PN en su investigación empírica Essai sur la qualification $d u$ travail (Naville, 1956a). Las empresas conformaban sus escalas de puestos en función de las habilitaciones efectivas que los sistemas de formación socialmente instituidos les colocaban más a mano. Circunstancia constatada posteriormente en innumerables ocasiones: puestos con idéntica tecnología en empresas situadas en territorios diferentes tiran de diferentes titulaciones ("electricistas" unas, "mecánicos" otras, por ejemplo) para reclutar a su personal. Las posiciones ocupadas por los puestos en las 
escalas de clasificación de la empresa varían entonces en función de las concepciones posibles de sus repartos entre diferentes procesos de formación (sancionados en sus valores relativos por los mercados de trabajo) y, con ellas, varían las cualificaciones mismas de los trabajadores dentro de las empresas y los sectores.

Inverosímil también, puesto que, en segundo lugar, todo en las formas de la producción y el consumo contemporáneos resulta sinónimo de "mutación" y no de "vaciamiento" o "degradación" relativos de una misma realidad esencialmente inalterable. Efectivamente, PN constata cómo tanto el número como la estructura y los tipos de puestos varían constantemente y, por su parte, también lo hacen los usos y necesidades sociales ; así como las capacidades laborales (niveles de formación) de los trabajadores. Con la aproximación sustancialista a la cualificación, aferrados a la persistencia del producto y de la necesidad social que se hallaría en su origen, perderíamos de vista lo esencial : cuando la producción industrial de ropa, por ejemplo, empieza a explotar materiales artificiales, buena parte de su fabricación se puebla con procesos de manipulación química, en estado fluido, de tejidos sintéticos; procesos (y conocimientos y habilidades aplicados a los mismos) que guardan más similitudes técnicas con la producción de plásticos, por ejemplo, que con los telares automáticos de principios de siglo. No habría pues más estabilidad a presuponer para los procesos de producción y para las necesidades sociales que aquella que nos exige una mirada que pretende deducirlo todo del taller. Es únicamente la persistencia de dicha mirada (la que pretende reconstruir, por ejemplo, una unidad para el proceso de trabajo a partir del producto final) la que nos invita a presuponer unos mismos puestos pasando de más sustancia (complejidad, conocimientos, experiencia, cualificación real, etc.) a menos sustancia ; pero... ¿de qué mismos puestos estamos hablando?

Efectivamente, si los contenidos de los puestos de trabajo han podido interpretarse como condicionando las características diferenciales de los trabajadores es porque la relación entre el trabajo y el trabajador la hemos observado invariablemente a través de la "situación de trabajo" : únicamente dados tales puestos y tales trabajadores en (y para) un instante determinado en un proceso de trabajo específico... nos es posible remitir sus ajustes, ya dados, bien a la tecnología y al puesto ("realmente"), bien a la formación y al trabajador ("formalmente"), de manera unilateral. Observada la misma relación en la duración y contemplando, también, los movimientos que sacuden la división social del trabajo, la cosa cambia : capacidades socializadas (a través de los sistemas educativos formales), esto es, aplicadas sobre los puestos (y cada vez más) dejan de valorizar la fuerza de trabajo de los trabajadores, y de traducirse en mejores cualificaciones para éstos, por culpa de las relaciones de competencia vigentes en los mercados de trabajo. PN formula empíricamente la demostración de hasta qué punto estas diferencias condicionan las clasificaciones y jerarquías de los puestos, en el interior de los establecimientos industriales, tomando como criterio sociológico para la estimación de las cualificaciones obreras los diferentes "tiempos de formación" [12].

En este caso, únicamente un cierre relativo y coyuntural de esos "mercados de trabajo" haría valer ideológicamente la coartada táctica de que las características de "nuestros" puestos requieren de un "nosotros" particular y no de un "ellos" cualquiera. Con el contenido del trabajo (el saber -mayor o menor- relativo al cómo se realiza el producto por parte del trabajador) como determinación esencial de una jerarquía natural entre el colectivo obrero, nos hallaríamos entonces ante una profecía autocumplida... aunque sólo en ocasiones, durante un tiempo y merced a la intervención indirecta sobre 
mecanismos sociales que, paradójicamente, dicha fórmula trataría de no reconocer o negar simbólicamente. En la aproximación sustancialista a la cualificación, casualmente, nuestros conceptos sociológicos calcan el sentido común obrero aplicado al asunto: al menos en los momentos en los que se trata, para los asalariados, de defenderse contra el desempleo, aferrándose a sus puestos de trabajo. Esta "casualidad" presenta, por supuesto, un sentido. Del mismo modo que con la unidad entre el trabajador y su trabajo, inmanente a la praxis, traducíamos la máxima obrerista de que toda la riqueza viene del trabajo, con la cualificación "realmente" determinada por el contenido del trabajo prolongamos esa misma máxima en lo relativo a los estatutos obreros (salarios y cualificaciones) : trabando implícitamente un concepto por el cual el valor "justo" y "verdadero" de los estatutos sociales obreros remitirían naturalmente al contenido de sus "trabajos". Esta continuidad entre el sentido común obrero y la Primera Formalización podría dar cuenta de buena parte de los obstáculos que, en su recepción y discusión, las obras de PN se encontraron en el momento de su edición. de PN hemos tratado de esbozar, la visibilidad de nuestro objeto (salariado) resultaría, sin embargo, inseparable del método que nos permite llegar hasta él. Pues lo que nuestras categorías (trabajo abstracto, por ejemplo) tratarían no consiste en atrapar supuestas esencias ocultas tras los fenómenos concretos sino de formalizar las relaciones subyacentes a ciertos procesos de transformación (movilidades y circulaciones). Esas relaciones no están dadas directamente en y por "lo real", son siempre relaciones a construir sociológicamente en la investigación. Más aún : los datos pertinentes resultan también magnitudes ya socialmente construidas, resultado de medidas sociales y, por ende, de la actuación de grupos y actores sociales. En este marco las transformaciones relativas a los modos de estructuración de los tiempos de la vida de los asalariados y las relativas a los modos de vertebración del conjunto de los intercambios sociales conformarían pues las cuestiones a investigar, problemáticas, por tanto, abiertas. Situación muy diferente a cuando, aferrados al concepto de "actividad humana ontológica", fundamos nuestras interpretaciones en su contraste con el "trabajo realmente existente" : las primeras (movilizaciones) son entonces supuestas como caracterizadas en el capitalismo por una supuesta "tendencia" a la 
descualificación, contraria al carácter "humano" del trabajo humano; los segundos (intercambios) son supuestos caracterizados en el capitalismo por otra supuesta "tendencia" ineluctable hacia su "mercantilización" absoluta, contraria a la norma y la cohesión propiamente "sociales".

Siguiendo algunos de los desarrollos de las obras de PN agrupadas en la colección Le Nouveau Leviathan (colección centrada en sendos estudios comparativos relativos al salariado en los países del este europeo -del así llamado, "socialismo real"- con el salariado de la Europa occidental contemporánea), principalmente los tomos Le salaire socialiste I (Naville, 1970a) y II (Naville, 1970b) y Les échanges socialistes (Naville, 1974), cabría, frente al esquema precedente, establecer otros puntos de partida para los análisis. El salariado no precisaría "descualificar", aún "tendencialmente", a todos los asalariados; tampoco borrar de la vida social toda regla o norma para sustituirla por relaciones "puramente" mercantiles. Aquí sólo estaríamos contemplando de entrada dos hipótesis : a) que la separación entre la fuerza de trabajo y el trabajo debe ser constantemente afirmada y reforzada a escala social : condición sine qua non para que los procesos productivos puedan ser permanente transformados con independencia de los trabajadores que ya operan sobre ellos ; b) que esa misma trasformación incesante de dichos procesos presenta el objetivo de alcanzar mayores niveles de productividad, esto es, de conseguir generar con un mismo tiempo de trabajo humano (valor) mayores cantidades de riqueza material: condición sine qua non para que la proporción del tiempo de plustrabajo del obrero aumente para cada mercancía producida en relación con el tiempo de trabajo necesario (el devuelto al obrero como equivalente al valor de su fuerza de trabajo).

Ambas ni suponen, ni implican, la descualificación "real" del trabajador en el taller sino la multiplicación exponencial de los ámbitos de movilidad laboral de los trabajadores sobre el conjunto de los puestos de trabajo existentes. Movilidad que hoy se desarrolla, socialmente hablando, ampliando las capacitaciones científico-técnicas de cada vez más asalariados (proceso que Marx significaba en 1847 como preparando el fin de todos "los idiotismos de oficio"); y, productivamente hablando, automatizando los procesos de trabajo: proceso que conlleva la multiplicación de nuevos puestos ligados a la manipulación de signos (mantenimiento, organización, programación, supervisión, etc,). Tampoco implicarían una mercantilización absoluta de todos los intercambios sociales. Al recortarse el tiempo de trabajo humano inmediato en la producción en favor del capital constante, de la maquinaria y la tecnología, los intercambios de bienes y servicios en términos de equivalencia se topan con la obligación, para su perpetuación, de apoyarse cada vez más en distribuciones y repartos dirigidos por medidas y estimaciones relativas a los usos y a las necesidades sociales. La producción de bienes y servicios en calidad de valores de cambio implica así, poco a poco, la extensión de las distribuciones y repartos de cada vez más bienes y servicios en términos de valores de uso : tal sería el proceso abierto tras la Segunda Guerra Mundial por la socialización del salario [13]. Más aún : las relaciones "de mercado" se sostienen y reproducen sobre reglas y planificaciones $\left[{ }^{14}\right]$ que implican a clases amplias de usuarios y sus necesidades, colectivos profesionales de asalariados, instituciones públicas diversas (ayuntamientos, gobiernos regionales, universidades y centros de formación e investigación, agencias nacionales e internacionales, etc.), firmas privadas, protocolos y estándares internacionales de fabricación, etc. Esas reglas no se han acabado tras la crisis y el colapso de las políticas desarrollistas keynesianas : más bien sus ámbitos de actuación se han descentralizado y multiplicado exponencialmente en la medida en la 
que los mercados, a sostener y a ampliar, han pasado de ser los internos y/o nacionales para extenderse a lo largo de múltiples Estados y continentes.

De este modo, las dos hipótesis que aquí hemos considerado no arman una mecánica "económica" unilateral e ineluctable (descualificación, mercantilización), sino un movimiento (indistintamente social y económico -la economía no es más que un particular modo de existencia de las relaciones sociales en la modernidad-) contradictorio, para el cual la única forma de desarrollo pasa por la disolución progresiva de sus propias condiciones de posibilidad (el tiempo de trabajo humano como fuente de los valores y criterio, por ello, de estructuración de todos los tiempos y los repartos sociales). Este movimiento contradictorio nos marca un horizonte de lo posible en el cual la única antítesis real del trabajo asalariado es el no-trabajo (y ya no la restitución de un trabajopraxis ontológico) [ $\left.{ }^{15}\right]$.

Nos hemos ido impidiendo así, paso a paso, siguiendo los análisis navillianos, la apelación a factores externos presupuestos (el "trabajo"; lo "social"), de carácter sustancialista y acrónico, con los que tratar de metamorfosear nuestras explicaciones en interpretaciones de carácter normativo: las relativas a la distancia entre un deber ser necesario (la praxis, la cohesión) y un ser contingente (la alienación, la anomia). No habría, según este otro modo de formalización, vía directa e inmediata al conocimiento de los modos de transformación de lo colectivo que no corriese el riesgo de acabar presuponiendo "lo social" mismo: aquello que se trataría, en rigor, de investigar. En palabras del joven Nietzsche: "si alguien esconde una cosa detrás de un matorral, a continuación busca en ese mismo sito y, además la encuentra, no hay mucho de qué vanagloriarse en esa búsqueda y ese descubrimiento" (Nietzsche, 1980, p. 12). Si no queremos arriesgarnos a permanecer prisioneros de mecánicas de construcción inconscientes, los sociólogos del trabajo habríamos de tomar conciencia reflexivamente del carácter netamente construido de nuestras problemáticas. Pero tratar de formalizar explícitamente relaciones nos llevaría quizás a niveles de abstracción demasiado grandes, obligándonos a considerar temporalidades que no son las de las vidas particulares de los actores... Con lo que correríamos el riesgo de perder interlocutores potenciales. Tampoco dispondríamos ya de cadenas de causalidad unívocas que nos permitiesen determinar en términos absolutos los sentidos previsibles del movimiento de salarios, estatutos, cualificaciones y tecnologías... Con lo que nuestro discurso se vería obligado más a reformular que a tratar de responder, una por una, a preguntas deudoras de las urgencias que el día a día plantea a los actores.

De aquí quizás que, desde la década de los noventa, los argumentos de la Sociología del Empleo, tras retomar (al hilo de los desarrollos de la economía institucionalista) la centralidad sociológica de los mercados de trabajo, den usualmente un giro de 180 grados, no menos llamativo. El de la reivindicación heurística del carácter "actorial" presuntamente implicado en la movilización y uso de la fuerza de trabajo [16]. Bajo la conocida fórmula : "los mercados de trabajo están socialmente construidos" (lo que, en sí, no es más que una tautología : para la sociología toda problemática ha de mostrarse, necesariamente, como "socialmente construida"). Con ello, correríamos de nuevo el riesgo de desembarazarnos definitivamente del análisis del carácter socialmente específico de los intercambios (esto es, del salario), para volver, lo más rápidamente que nos ha sido posible, a nuevos fenómenos autoevidentes (normas y reglas, ligadas con la actuación de instituciones) presumiblemente determinados, en su configuración particular, por esencias (en este caso, "culturales" : los "intereses" y "valores" de los actores) con las 
que saturar, de nuevo, desde un principio, los horizontes hacia los que se movería nuestro objeto (la necesaria restitución de un empleo "normal", ligado con la cohesión social y los derechos de ciudadanía, herramienta ineludible para la pacificación de todos los conflictos sociales).

Si la Sociología del Empleo (Paola Villa, Margaret Maruani, Robert Castel, etc.) nos ha venido advirtiendo, con rotundidad, de la necesidad de incorporar (como algo más que variables dependientes o contextuales) los ámbitos reproductivos en los análisis, quizás sus modos de operar más usuales sigan adoleciendo de una formalización explícita de las relaciones y de las temporalidades implicadas en el funcionamiento de los mercados de trabajo. Todo parece indicar que la tendencia es la de sustituir la construcción explícita de dichas relaciones ya no por el "trabajo" sino por las "normas", y localizar los datos relevantes ya no en la "situación de trabajo" sino en tales o cuales "mercados de trabajo" (socialmente construidos), mercados en donde el ajuste entre determinadas fuerzas de trabajo y determinados empleos está ya dado. De aquí a la "explicación" del modo de cambiar "del empleo" como producto de unas u otras "culturas" o "valores" (machistas, xenófobos, igualitarios, neoliberales, solidaristas, etc.) por parte de los agentes operantes en su "construcción", no hay más que un paso. "Explicación" que supone la "cohesión social" como un hecho (si bien ésta se encontraría coyunturalmente indispuesta) y su futura recuperación como de obligado cumplimiento : el modelo establecido por el "trabajo completo o normal" (por la praxis) es aquí sustituido por la solidaridad orgánica durkheimniana, la alienación por la anomia. De este modo los conflictos y contradicciones sociales son denunciados para su inmediata superación en el papel por obra y gracia de la Teoría.

A nuestro juicio la principal fuerza de la sociología del salariado de PN (para la cual el movimiento conjunto de las formas y las instituciones del trabajo debería analizarse a partir de la relación primordial por la cual la actividad humana, asociada condicionalmente a los modos de producción, se transforma en trabajo), remite precisamente a su renuncia explícita a constituir una Teoría de ese tipo. Teoría por la cual todos los hechos relevantes lo serían en la medida en la que pudiesen ser referidos a una totalidad o estructura previa, supuestamente conocida : todo acontecimiento (por ejemplo, la precarización del empleo, la crisis del Estado del Bienestar, la flexibilización de los mercados de trabajo, el repunte del desempleo, etc.) se convierte así en una ilustración o en una consecuencia de un principio (por ejemplo, "lo económico"; "lo social") declarado más amplio y que, sin embargo, no presenta, de hecho, otro contenido que dichos acontecimientos (procesos de mercantilización/procesos de planificación normada). Los análisis propuestos por PN lo largo de cinco décadas no partían de realidades dadas por conocidas (bien el "trabajo realmente existente"; bien los "actores", las "instituciones", las "normas", etc.) sino que se ocupaba de formalizar las relaciones que las vinculan y las constituyen [ $\left.{ }^{17}\right]$.

De esta forma, hemos comenzado con preguntas, las reformulamos después, para acabar con nuevas preguntas, al final. Procedimiento quizás decepcionante para algunos (los acostumbrados a adscribir a la teoría el papel de herramienta hermenéutica onmicomprensiva, matriz generadora de un número potencialmente infinito de respuestas concluyentes -y no de hipótesis localizadas en un tiempo y un espacio sociales determinados en función de diferentes objetos formales-) y demasiado ambicioso para otros (los convencidos en la futilidad de todo intento de explicación y entregados a una sociología descriptiva limitada a la interpretación de objetos "reales", 
dados y evidentes). En cualquier caso, para nosotros, el delimitar el campo de nuestras incertidumbres es, también, contribuir a la delimitación un objeto de la ciencia tanto como el identificar la estructura de nuestras preguntas es, también, aproximarnos a la definición de un método.

\section{BIBLIOGRAFÍA}

Naville, P. (1954) : La vie de travail et ses problèmes. Paris : Armand Colin.

Naville, P. (1956a) : Essai sur la qualification du travail. Paris : Marcel Rivière.

Naville, P. (1956b) : L'investissement des capitaux dans les industries hautement automatisées. Liaisons sociales, 31, 20-21.

Naville, P. (1956c) : Les implications de l'automation pour l'apprentissage. L'enseignement technique, octobre/décembre, 73-83.

Naville, P. (1957) : De l'aliénation à la jouissance. Genèse de la sociologie du travail chez Marx et Engels. Paris : Marcel Rivière.

Naville, P. (1958a) : Vues préliminaires sur les conséquences du développement de l'automation pour la main d'œuvre industrielle. Cahiers d'études de l'automation, 2, 3-25.

Naville, P. (1958b) : La structure de l'emploi et l'automation. Bulletin International des Sciences Sociales, vol. $X, 1,17-30$.

Naville, P. (1958c) : Le développement de l'automation et le travail des ouvriers d'entretien. Droit Social, vol. 20, 2, 81-89.

Naville, P. (1958d) : Les conséquences sociales de l'automation. Bulletin international des Sciences Sociales, vol. XI, 7-68.

Naville, P. (1960) : Vers l'automatisme social. Revue Française de Sociologie, 3, 275-285.

Naville, P. (1961) : La mesure du niveau d'automatisation dans l'industrie. Sciences, janvier/février, 59-70.

Naville, P. (1962) : Nouvelles recherches sur la division du travail. Cahiers d'étude de l'automation et des sociétés industrielles, 3, 7-18.

Naville, P. (1963) : Réflexions à propos de la division du travail. Cahiers d'étude de l'automation et des sociétés industrielles, 4, 232-244.

Naville, P. (1964) : La théorie des trois secteurs et l'évolution sociale. Cahiers d'étude des sociétés industrielles et de l'automation, 5, 137-168.

Naville, P. (1967a) : Remarques sur les relations entre la formation scolaire et professionnelle et la forme de l'emploi. Cahiers d'étude des sociétés industrielles et de l'automation, 8, 51-62.

Naville, P. (1967b) : Diachronie, synchronie et structure. Cahiers d'étude des sociétés industrielles et del'automation, 8, 151-176. 
Naville, P. (1970a) : Le Nouveau Léviathan. Le salaire socialiste I. Les rapports de production. Paris : Anthropos.

Naville, P. (1970b) : Le Nouveau Léviathan. Le salaire socialiste II. Sur l'histoire moderne des théories de la valeur et de la plus-value. Paris : Anthropos.

Naville, P (1972a) : Temps et technique. Les structures de la vie de travail. Genève : Droz.

Naville, P. (1972b) : Le Nouveau Léviathan, tome V. La bureaucratie et la révolution. Paris : Antrophos.

Naville, P. (1974) : Le Nouveau Léviathan, tome IV. Les échanges socialistes. Paris : Anthropos.

Naville, P. (1978a [1961]) : El método en la sociología del trabajo. En Friedmann, G. ; Naville, P.

(dir.) : Tratado de sociología del trabajo I (pp. 36-65). México DF : FCE.

Naville, P. (1978b [1961]) : El empleo, el oficio, la profesión. En Friedmann, G. y Naville, P. (dir.) :

Tratado de sociología del trabajo I (pp. 230-237). México DF : FCE.

Naville, P. (1978c [1961]) : Población activa y teoría de la ocupación. En Friedmann, G. ; Naville, P. (dir.) : Tratado de sociología del trabajo I (pp. 143-175). México DF : FCE.

Naville, P. (1978d [1961]) : El progreso técnico, la evolución del trabajo y la organización de la empresa. En Friedmann, G. y Naville, P. (dir.) ; Tratado de sociología del trabajo I (pp. 369-384). México DF : FCE.

Naville, P. (1978e [1962]) : El trabajo asalariado y su valor. En Friedmann, G. ; Naville, P. (dir.) : Tratado de sociología del trabajo II (pp. 113-134). México DF : FCE.

Naville, P. (1979-80) : Qu'est-ce-que la qualification du travail ?. L'Année Sociologique, 30, 497-503.

Naville, P. (1980) : Le temps, la technique et l'autogestion. Paris : Syros.

Naville, P. (1981) : Du nouveau sur la division du travail. L’Année Sociologique, 31, 513-517.

Naville, P. (1982) : Sociologie et logique. Esquisse d'une théorie des relations. Paris : PUF.

Naville, P. (1984) : La maîtrise du salariat. Paris : Anthropos.

Naville, P. (1985 [1963]) : ¿Hacia el automatismo social ? Problemas del trabajo y de la automación.

México DF. : FCE :

Naville, P. (1991) : Sociologie d'aujourd'hui. Nouveaux temps, nouveaux problèmes. Paris : Anthropos.

Naville, P. ; Barrier, C. ; Cordier, C. ; Grossin, W. ; Lahalle, D. ; Legotien, H. ; Palierne, H. ; Moisy, B. \& Wackermann, G. (1961) : Automation et travail humain. Paris : CNRS.

Naville, P. \& Rolle, P., (1978 [1961]) : La evolución técnica y sus repercusiones en la vida social. En Friedmann, G. ; Naville, P. (dir.) : Tratado de sociología del trabajo I (pp. 345-368). México DF : FCE.

Boulayoune, A. \& Jacquot, L. (2008). Figures du salariat: Penser les mutations du travail et de l'emploi dans le capitalisme contemporaine. Paris : L'Harmattan,

Burnier, M. ; Célérier, S. \& Spurk, J. (1997). Des sociologues face à Pierre Naville ou l'archipel des savoirs. Paris : L'Harmattan.

Campinos-Dubernet, M. \& Marry, C. (1986). La qualification. En Tanguy, L. (dir.) : L'introuvable relation formation - emploi. Un état des recherches en France (pp. 197-232). Paris : La Documentation Française.

Cuenot, A. (2007) . Pierre Naville (1904-1993) : Biographie d'un révolutionnaire marxiste. Nice : Bénévent Éditions. 
De Coster, M. \& Pichault, F. (éds.)(1998 [1994]). Traité de sociologie du travail. Paris-Bruxeles : De Boeck.

Durand, C.; Prestat, C. \& Willener, A. (1958). Niveau de mécanisation et mode de rémunération. Paris : ISST.

Éliard, M. (1996). Naville, la passion de la connaissance. Toulouse : Presses Universitaires du Mirail.

Erbès-Seguin, S. (1999). Sociologie du travail. Paris : La Découverte.

Freyssinet, J. (2005). Quels acteurs et quel niveaux pertinents de représentation dans un système productif en restructuration ?. La revue de l'IRES, 47, 319-336.

Friedmann, G. (1946). Problèmes humaines du machinisme industrielle. Paris : Gallimard.

Friedmann, G. (1962). Proudhonnien ? Optimiste ? Sociologie du travail, 4, 395-399.

Friedmann, G. (1978 [1961]). El objeto de la sociología del trabajo. En Friedmann G. y Naville. P. (dir.) : Tratado de Sociología del Trabajo I (pp. 13-35). México DF : FCE.

Heinrich, M (2008). Critica de la Economía Política. Una introducción al El Capital de Marx. Madrid : Escolar y Mayo.

Nietzsche, F. (1980). Sobre verdad y mentira en sentido extramoral, Valencia : Teorema.

Pillon, T. \& Vatin, F. (2007). Traité de sociologie du travail. Paris : Octares.

Postone, M. (2006). Tiempo, trabajo y dominación social. Una reinterpretación de la teoría crítica de Marx. Madrid : Marcial Pons.

Rolle, P. (1988). Travail et salariat. Bilan du Sociologie du travail. Grenoble : Presses Universitaires.

Rose, M. (1988). Industrial Behaviour. Research and control. London : Penguin Books.

Sánchez Moral, S. ; Méndez Gutiérrez del Valle, R., Michelini Falabella, J-J., \& Méndez Gutiérrez del Valle, R. (2008). El empleo industrial en la metrópolis postindustrial : tendencias actuales en la ciudad de Madrid. Scripta Nova. Revista Electrónica de Geografía y Ciencias Sociales, vol. XII, 270-115 (de http://www.ub.es/geocrit/sn/sn-270/sn-270-115.htm)

Stroobants, M. (1994). Sociologie du Travail. Paris Nathan.

Tanguy, L. (2001). Questions sur le travail du sociologue. En Pouchet, Amélie (coord.) ; Sociologie du travail : 40 ans après, Paris : Elsevier.

Touraine, A. (1955). L'évolution du travail ouvrier aux usines Renault. Paris : Éditions du CNRS.

Vatin, F. \& Bernard, S. (dir.) (2007). Le salariat : théorie, histoire et formes. Paris : La Dispute.

\section{NOTAS}

1. Este título es similar (La société peut-elle se comprendre par le travail ?) al planteado en la tercera mesa redonda del reciente coloquio "Autour de Pierre Naville“ , celebrado en Bruselas (ULB) el 22 de febrero del 2008 (para más información ver: http://dev.ulb.ac.be/tef/naville/ index.php?option=com_frontpage\&Itemid=1). Mesa en la que tuve el placer de participar junto a François Vatin y Marcelle Stroobants.

2. Basta señalar al respecto la celeridad con la que la actual crisis económica mundial ha reactivado de nuevo en el Reino de España la axiomática esencial de los discursos trabajistas en el ámbito de las ciencias sociales (Derecho y Sociología, fundamentalmente). Si bien se trata de un manifiesto ("de los 700") - en repuesta al publicado por 100 economistas liberales sobre la 
necesidad de una reforma del mercado de trabajo nacional orientada al abaratamiento del despido-, El trabajo: fundamento de un crecimiento económico sostenible (ver: http:// www.elpais.com/elpaismedia/diario/media/200906/20/economia/ 20090620elpepieco_1_Pes_PDF.pdf) insiste en la centralidad y actualidad del trabajo concreto y de sus prestatarios, los trabajadores, fuentes, en última instancia, del "progreso económico" de la nación.

3. La repercusión de la obra de PN en el ámbito de la Sociología del Trabajo en Francia ha venido siendo bastante significativa en los últimos decenios. Ya en 1986, Myriam Campinos-Dubernet y Catherine Marry, reivindicaban en un amplio capítulo, dentro la obra colectiva, L'introuvable relation formation-emploi, la importancia y actualidad de las posturas mantenidas por el autor a propósito del análisis sociológico de la cualificación, frente a las de Georges Friedmann (Campinos-Dubernet \& Marry, 1986). Tras su muerte en 1993 su importancia simbólica en la sociología aplicada al estudio del trabajo en el país vecino no ha hecho más que ampliarse. Dos libros colectivos dedicados en 1996 y 1997 a la obra sociológica del autor, Naville, la pasión de la connaissance (Éliard, 1996) y Des sociologues face à Pierre Naville ou l'archipiel des savoirs (Burnier, Célérier \& Spurk, 1997) ; una biografía “política” (Cuenot, 2008) ; así como un centro de investigaciones del CNRS que ha sido bautizado con su nombre (Centre Pierre Naville) certifican este renacer simbólico del significante "Naville" en la sociología francesa actual. Dos textos de carácter divulgativo (Stroobants, 1994 ; Erbès-Seguin, 1999), así como dos grandes manuales (De Coster \& Pichault, 1994 ; Pillon \& Vatin, 2007) acerca de la Sociología del Trabajo dedican bien capítulos enteros bien varias páginas, a resumir unas posiciones que parecen formar parte ya del acerbo asumido como el propio de, y de obligada referencia para, la especialidad. Más interesantes si caben resultan dos obras colectivas de reciente aparición, Le salariat: théorie, histoire et formes (Vatin \& Bernard, 2007) y Figures du salariat : Penser les mutations du travail et de l'emploi dans le capitalisme contemporaine (Boulayoune \& Jacquot, 2008), en donde no sólo se revindica, en total sintonía con la aproximación navilliana, la necesidad de una sociología del salariado sino que se desarrollan aportaciones empíricas originales en torno a transformaciones actuales.

4. Recordemos, al respecto, la primera definición en Europa de ése, su objeto de estudio, en el momento de su consagración institucional en Francia, en el Traité de Sociologie du Travail : : "el estudio, en sus diversos aspectos, de todas las colectividades humanas que se constituyen con motivo del trabajo" (Friedmann, 1978 [1961], p. 28) ; definición que se completa en el prólogo de la obra con : "de las reacciones que ejercen sobre ellas, en los diversos planos, las actividades de trabajo constantemente remodeladas por el progreso técnico, de las relaciones externas, entre ellas, e internas, de los individuos que las componen" (Íbíd., p. 7). En otras palabras, partiendo de individuos relacionados en el interior de colectividades que, a su vez, se relacionan entre sí, la Sociología del Trabajo se encargaría del estudio de aquellas colectividades supuestas como constituidas para, y que reaccionarían permanentemente a, las mutaciones sufridas por el "trabajo". Trabajo sinónimo aquí de actividades de trabajo cuyas transformaciones remitirían a su constante moldeado "por el progreso técnico". Y así, resumiendo, pretendidamente, al Marx de El Capital, Friedmann concluía: "El trabajo es, esencialmente, a través de la técnica, la transformación que hace el hombre de la naturaleza que, a su vez, reacciona sobre el hombre modificándolo" (Ibíd., p. 14.). A lo que, un poco más adelante, agrega : “en esta interacción entre el hombre y su medio (más o menos natural) a través de la técnica parece residir, a fin de cuentas, el elemento motor que explica la evolución o la revolución de las estructuras sociales" (Ibíd.).

5. La propuesta de reconstrucción teórica del objeto del estudio (salariado) que se defiende aquí, en contraste con el propio de la Sociología del Trabajo ("trabajo"), instituye dos métodos opuestos. Éstos son significados por Pierre Rolle, en Travail et salariat, como dos modos de "formalización". La Primera Formalización (PF) : a) supone que el trabajador se define por su "trabajo", y se interesa por las relaciones del trabajador consigo mismo y con los otros a través de 
su "trabajo"; b) se pregunta por qué el trabajador se opone a su "trabajo"; y, c) parte de la fusión, de la armonía y espera su reconstitución : el trabajador volvería a encontrar su autonomía y su poder en el "trabajo". La Segunda Formalización (SF) : a) supone que los comportamientos de los individuos son movilizados por un mecanismo que le asegura como contrapartida bienes y servicios, mecanismo que constituye al trabajador al mismo tiempo que la estructura del colectivo ; b) se interesa por las relaciones entre los grupos sociales y el reparto de tareas que entre ellos se produce y busca identificar y comprender cómo el trabajador ha sido emparejado con su tarea ; y, c) parte de que los lazos del asalariado con su empleo se disolverán hasta el punto en el cual podrán ser dominados colectivamente y la comunidad humana se organizará más allá de las estructuras definidas por trabajo (Rolle, 1988, p. 44).

6. El debate entre Marx y Proudhon resurgió coyunturalmente, por iniciativa de PN, en el contexto de la primera institucionalización en Francia de la Sociología del Trabajo. En un artículo publicado en 1962 (Naville, 1962) PN polemizaba con Problèmes humaines du machinisme industriel, de Georges Friedmann (Friedmann, 1946), L'évolution du travail ouvrier aux usines Renault, de Alain Touraine (Touraine, 1955) y Niveau de mécanisation et mode de rémunération, de Claude Durand (Durand, Prestat \& Willener, 1958). PN se apoyaba ahí en Ure y Babbage para pensar la automatización y, como Marx, criticará el esquema de inspiración hegeliana según el cual el maquinismo podría "recomponer el trabajo". Por último, invitará a los sociólogos a deshacerse del ideal artesanal. Friedmann responderá a PN con una breve reseña en Sociologie du travail : "Proudhonnien ? Optimiste ?" (Friedmann, 1962). La importancia de Proudhon para una cabal comprensión del método de la Sociología del Trabajo europea ha sido más recientemente reivindicada con contundencia por otros autores (Rose, 1988, 320).

7. En el mismo sentido se puede consultar también : Naville, 1967a, 1978b [1961], 1978c [1961], 1980, 1981 y 1984.

8. Este último aspecto, la reticularización del tejido productivo y la disolución de la empresa tradicional, está desarrollado en Naville \& Rolle, 1978 [1961]. Actualmente, existen indicios que hablan de una seria reconsideración, en el ámbito de las ciencias sociales, de la centralidad actual de la empresa desde el punto de vista del empleo, a pesar de los discursos apologéticos del emprendizaje y similares : por ejemplo, resulta cada vez más difícil la identificación de la empresa como organización productiva con la empresa en calidad de empleador y como centro de decisión estratégico respecto de la puesta en valor de un capital (Freyssinet, 2005).

9. Respecto a la automación resultan de interés los artículos monográficos publicados por PN antes de Hacia el automatismo social (Naville,1956b, 1956c, 1958a, 1958,b, 1958c, 1958d, 1960, 1961, 1963 y 1978d [1961]).

10. Lo que actualmente es ya un lugar común : la ilusión estadística según la cual los empleos de servicios relevan a los industriales (y en la que algunos han querido ver el advenimiento de, precisamente, una sociedad "postindustrial") ha venido enmascarando, en realidad, una mutación cualitativa en el interior mismo del sector industrial. Sector cada vez más caracterizado por una tercerización industrial del empleo: integración funcional de actividades que, en la práctica, desdibujan las fronteras entre sectores. Para una reciente demostración empírica basta consultar, por ejemplo, Sánchez Moral et al., 2008.

11. Puede consultarse, también, acerca de esta misma problemática : Naville, 1964.

12. Sobre la cualificación se puede tomar como una síntesis de su planteamiento: Naville, 1979-80.

13. En otras palabras, por detrás de la falsa dicotomía del mercado y la norma subsistiría en realidad otra más profunda: la que contrapone hoy en el capitalismo mundial los intercambios mercantiles y planificados de valores, impulsados por la acumulación de capital, a los intercambios planificados (repartos, distribuciones, escalas) de usos, servicios y de disfrutes, que esa misma acumulación contradictoriamente impulsa y exige como precondición necesaria para la continuación de los primeros. La creciente riqueza social cuya producción requiere de un 
tiempo de trabajo humano directo decreciente que permite recortes sustanciales y generalizables de la jornada de trabajo; puestos que no necesitan para ser ejecutados de unas competencias determinadas, ligadas a la experiencia ( $y$, merced a ello, escasas), componiendo funciones productivas que abonan nuevas posibilidades para el reparto social de ese tiempo de trabajo necesario ; redes de empresas cuyos elementos resultan intercambiables, en muy cortos períodos de tiempo, en función de los proyectos planteados, ampliando los ámbitos cualitativos de la determinación colectiva y democrática de los contenidos y fines de las políticas económicas y sociales, etc. Todos estos procesos hablan de la posibilidad de otras planificaciones más allá de los intercambios de valores y del trabajo asalariado, planificaciones democráticas, descentralizadas y de carácter experimental, que versen no sólo sobre medios y cantidades sino, simultáneamente, sobre fines y cualidades de usos, servicios y disfrutes: "Para que el consumo (los usos son sus diferentes formas) se convierta realmente en el fundamento y el fin de la producción es necesario que el sistema de usos y el intercambio de usos no se presenten más bajo la forma subordinada que actualmente es la suya. Esto supone obviamente una transformación de las constricciones que impone la escasez (por medio de una alta productividad), pero también una modificación radical, claramente explicitada, del sistema de necesidades. Estas deben pasar de su forma determinada, cuantitativa y cualitativamente, a una forma aleatoria que supone elección, indeterminación e innovación. Es decir, entre la anarquía y la constricción deberá elaborarse una concepción experimental de las necesidades y de su satisfacción. (...) Es la experimentación desembarazada de las trabas del intercambio de valores la que ofrece todas sus oportunidades a la cooperación y la asociación, sustituyendo las coerciones de un poder exterior a las sociedades y los cooperadores. Es cierto que esta tendencia a la experimentación se manifiesta ya con fuerza en las sociedades industriales avanzadas; viene impulsada por el papel creciente que juega la ciencia en los sistemas de producción y consumo, por la movilidad de los empleos, por la creciente productividad, la transformación de los sistemas educativos y pedagógicos de formación, y por muchos otros factores, comprendidos aquellos que se gobiernan actualmente bajo la expresión de ocios. Pero esta tendencia está al mismo tiempo trabada por factores contrarios, todos ellos ligados al sistema de intercambio de valores. (...) El uso, (...) por una metamorfosis real de la economía de mercado que instaure la primacía del servicio (...), debe restituir al trabajo productivo necesario su propio carácter de servicio, es decir, entrañar la supresión del salariado. Cuando el ejercicio del trabajo se haya convertido realmente en un servicio común, ejercido algunas horas al día, entonces toda la cadena de servicios se convertirá en la trama común, por períodos asignables, tanto de la actividad privada como de la colectiva. Es entonces también cuando el intercambio de experiencias, de una nueva forma de comunicación, podrá instaurarse, suscitando en lo sucesivo tantos problemas nuevos como antiguos haya eliminado" (Naville, 1974, p. 219-10, 213, traducción libre).

14. Acerca de la imbricación entre el mercado y la norma, para PN la regulación planificada de los intercambios practicada en, por ejemplo, el socialismo de Estado conllevaba mecanismos de competencia y se llevaba a cabo a través de ellos: "Que haya economía de mercado no significa que domine la elección sino el intercambio, y el intercambio está ligado a la existencia de un valor. Intercambio y valor se implican mutuamente. Si hay uno hay otro, y esta existencia implica un mercado regulado por precios de mercado. (...) Allí donde actualmente el Estado interviene, reglamenta e impone, cerramos los ojos a menudo ante la materia misma de su acción: el intercambio de valores" (Naville, 1974, p. 236, traducción libre). Mecanismos sobre los cuáles los Estados trataban de intervenir por medio de la planificación, sin pretender, no obstante, suprimirlos: "la propiedad estatal no abole la competencia : cambia sus formas gracias a la planificación” (Íbid., p. 495, traducción libre). Así, por ejemplo, la planificación de la economía en la Unión Soviética habría consistido en la puesta en relación, mediante una mecánica administrativa centralizada, de unidades productivas independientes y dispersas con el objetivo de poner en competencia sus procedimientos productivos. Competencia entre procesos que se 
realizaba a través de la comparación, evaluación y homologación, al alza, de sus resultados medios. Mediante esta mecánica, los beneficios de la totalidad de las unidades se repartirán, finalmente, entre ellas, atendiendo al cumplimiento, mayor o menor, de los resultados conquistados (registro), tras las determinaciones previas por parte del plan de los resultados alcanzables (prescripción). Dicho en otras palabras: la planificación constituía un auténtico mecanismo orientado a determinar el tiempo de trabajo socialmente necesario para producir unas y otras mercancías. Lo cual permitía, al mismo tiempo, señalar los niveles medios de desarrollo organizativo, social y tecnológico operantes, de cara a fijar, por último, los fondos salariales, de reposición de maquinaria, etc., asignables a unos u otros sectores y empresas para su eventual reproducción ampliada. Es decir, exactamente el grueso de las operaciones que en nuestras particulares sociedades salariales efectúan los mercados "realmente existentes" (mercados también normados y regulados). Operaciones que, en un caso y otro, alimentan ese proceso social permanente de comparación, homologación y medida de todas las actividades productoras de mercancías -bienes y servicios destinados a su intercambio en términos de equivalencias en valor- que Marx llamaba trabajo abstracto. Es por todo ello que "la existencia de un plan económico nacional, fundado en una propiedad estatal generalizada, no basta para disolver, aún progresivamente, las relaciones de mercado. En ciertas condiciones puede incluso reforzarlas y estabilizarlas, sustrayéndolas a las crisis que sufren en la economía capitalistaburguesa. Plantear la planificación como antítesis directa del mercado no es suficiente para transformar las mercancías en simples productos. (...) Todo lo que podemos afirmar es que las relaciones de valor (mercantil) son sometidas, merced al plan, a nuevas condiciones; se ejercen por medio de una especie de peritaje central, pero no desaparecen por ello. Las discusiones que se sucedieron en la URSS sobre las modalidades de la planificación no tenían por objeto el mejor medio para acelerar la extinción de las relaciones de mercado, sino el mejor medio para reglamentarlas, lo que contribuye, más bien, a perpetuarlas" (Íbid., p. 476, traducción libre).

15. Para PN identificar el dinamismo de lo colectivo supone tratar de dar cuenta del mecanismo por el cual la actividad es movilizada, modelada y distribuida en el proceso de producción y reproducción, mecanismo que se expresa, paradójicamente, a través de la amenaza permanente de disolución de cada modalidad concreta de trabajo. E incluso más allá: por el recorte incansable del tiempo de trabajo humano inmediato consumido en la creación de un conjunto cada vez mayor de riquezas materiales. Precisamente, PN concluye su temprano recorrido por las categorías marxianas con la única polaridad que, entiende, encierra una contradicción antitética; la que Marx establece entre "trabajo" y "no-trabajo" : "Una sociedad, un modo de trabajo, que evolucionan, se critican ellos mismos. Dilucidar su estructura funcional, es dilucidar así el sentido en el cual ésta evoluciona, las contradicciones más profundas que esta contiene, la crítica que ella representa frente a sí misma. (...) la antítesis fundamental del trabajo no es el trabajo mejorado o valorizado sino el no-trabajo" (Naville, 1957, p. 492, 489, traducción libre).

16. Lucie Tanguy señala muy bien los contornos con los que se ha venido manifestando este mismo giro "actorial" en la Sociología del Trabajo empírica francesa posterior a la década de 1990 : "la sociología del trabajo se interesa hoy más en la organización del trabajo, en la organización de las empresas, que en las relaciones sociales de trabajo que constituían el ángulo de aproximación privilegiado en el cuarto de siglo posterior a la postguerra, y que englobaban el análisis de las condiciones de trabajo, de las relaciones en el trabajo, los salarios, los comportamientos de los trabajadores, sus modos de organización y sus universos culturales, etc. Aproximándose a una sociología de las organizaciones, la sociología del trabajo se ha liberado de ese tipo de análisis anclado en las relaciones entre clases o entre grupos de individuos caracterizados por sus estatus, sus posiciones en una jerarquía, sus edades, sus sexos, sus orígenes étnicos, etc. Este desistimiento de las nociones de grupos y clases en beneficio del de actor, si bien comprendido de formas muy diferentes, es el que me parece necesario interrogar. ¿Expresa amnesia, la resolución de un problema científico o su abandono, dado que no ha habido 
respuesta aceptable por todos y que el realismo empírico ha de prevalecer ? (...) Se admitirá [en todo caso] que conviene interrogarse sobre los costes del abandono de una noción básica [, las relaciones sociales de trabajo,] que nos priva de los medios de acceder a un análisis de las transformaciones de la estructura social" (Tanguy, 2001, p. 328, traducción libre).

17. Resta subrayar que el que este trabajo se haya articulado en torno a las cuestiones de método no es en absoluto ca-sual : estas mismas cuestiones resultan omnipresentes a lo largo y ancho de la obra de PN, empezando por su capítulo introductorio en el Traité de Sociologie du Travail de 1961 -donde Friedmann dedicaba el suyo al "trabajo" de una sociología del trabajo, PN hacia lo propio con el "método" asociable a una teoría sociológica articulable en torno al trabajo- (Naville, 1978a [1971]) y artículos enteros en la revista Cahiers d'étude des sociétés industrielles et de 1 'automation (Naville, 1967b), hasta su obra tardía centrada en la posibilidad de una formalización lógico-matemática adecuada a una teorización sociológica en clave relacional (Naville, 1982 y 1991), pasando por la fundación y di-rección de la revista Epistémologie sociologique (1969-1972).

\section{RESÚMENES}

Este artículo introduce algunas de las obras e investigaciones de Pierre Naville (1904-1993) en materia de empleo, automación y cualificación. Apoyándose en ellas trata de problematizar críticamente el modo de construcción del objeto característico de la Sociología del trabajo clásica. Defiende que el trabajo sociológicamente relevante remite a una mediación social general, como el concepto de "trabajo abstracto" lo hace en el Marx tardío. También defiende que la sociología que podría utilizar dicho "trabajo" no conformaría propiamente una especialidad al uso sino una articulación sistemática de hipótesis dirigidas a arrojar luz de forma contrastable (a partir de investigaciones empíricas) sobre las lógicas de lo social, esto es, una socio-logía a secas.

Este artigo introduz algumas das obras e investigações de Pierre Naville (1904-1993) em matéria de emprego, automatização e qualificação. Apoiando-se nelas, procura problematizar criticamente o modo de construção do objecto característico da Sociologia do trabalho clássica. Defende que o trabalho sociologicamente relevante remete para uma mediação social geral, à semelhança do que faz o conceito de "trabalho abstracto" nos escritos tardios de Marx. Também defende que a sociologia que poderia utilizar este "trabalho" não consistiria propriamente numa especialidade mas uma articulação sistemática de hipóteses destinadas a clarificar de forma contrastante (a partir de investigações empíricas) as lógicas do social, isto é, uma socio-logia.

Cet article a pour objectif de situer quelques unes des œuvres et recherches de Pierre Naville (1904-1993) qui ont trait à l'emploi, l'automatisation et la qualification. A partir de celles-ci, on cherche à problématiser de façon critique le mode de construction de ce qui constitue l'objet caractéristique de la Sociologie du travail classique. On défend que le travail qui est relevant sur le plan sociologique convoque une médiation sociale générale, de la même façon que le fait le “travail abstrait » dans les écrits de Marx. On défend également que la sociologie qui pourrait utiliser ce “travail» n'est pas une spécialité mais bien une articulation systématique d'hypothèses destinées à clarifier par des effets de contraste (au départ de recherches empiriques) les logiques du social, à savoir : une socio-logie.

This article introduces some of the work and sociological research of Pierre Naville (1904-1993) on employment and automation skills. On the basis of Naville's research, this paper aims to 
discuss critically the construction of the object characteristic of the classical Sociology of Work. It argues that sociologically relevant 'work' is one which refers to a general social mediation, similar to the concept of 'abstract work' in the late writings of Marx. It also defends that the sociology that could make good use of this 'abstract work' isn't a speciality 'but a systematic articulation of hypothesis designed to clarify as a contrast (by means of empirical research) the logics of the social, that is, a socio-logy.

\section{ÍNDICE}

Palabras claves: Pierre Naville, sociología del trabajo, sociología del empleo, salariado, trabajo abstracto, automación, cualificación

Keywords: Pierre Naville, sociology of work, sociology of employment, abstract work, automation, qualification

Mots-clés: Pierre Naville, sociologie du travail, sociologie de l'emploi, salariat, travail abstrait, automation, qualification

Palavras-chave: Pierre Naville, sociologia do trabalho, sociologia do emprego, assalariado, trabalho abstracto, automação, qualificação

\section{AUTOR}

\section{JORGE GARCÍA LÓPEZ}

Facultad de Derecho y Ciencias Sociales de la UCLM (Universidad de Castilla-La Mancha). Ronda de Toledo s/n, 13071 Ciudad Real. España

jorge.García@uclm.es 